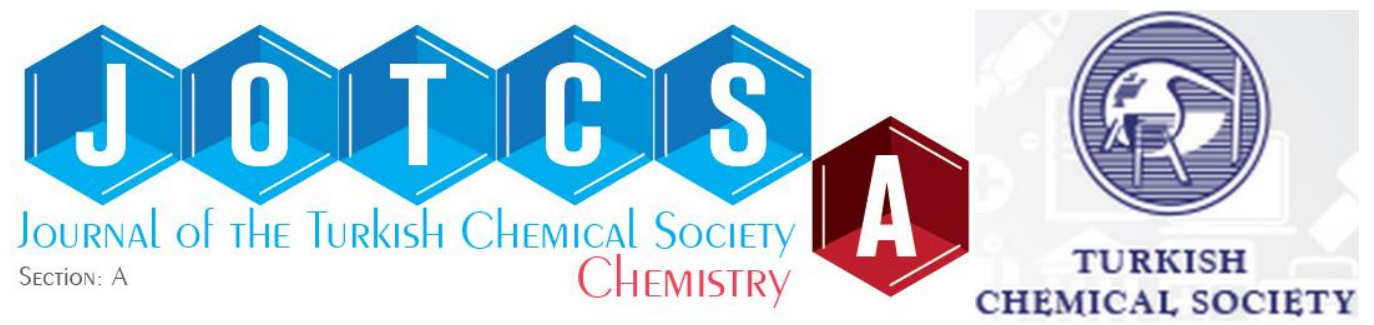

\title{
Transition Metal Doped Solid Oxide Fuel Cell Cathodes
}

\author{
Ayşenur Eslem Kısa ${ }^{1}$, Oktay Demircan ${ }^{1, *}$ \\ ${ }^{1}$ Department of Chemistry, Faculty of Arts and Science, Boğaziçi University, İstanbul, Turkey.
}

Abstract: Fuel cells have developed of excessive interest as a probable economical, efficient, and clean candidate for alternative and environmental friendly power generation services. Solid Oxide Fuel Cell (SOFC) is an elevated temperature fuel cell, dealing with power generation as well as heat. Up to now many studies have been made to replace platinum, $\mathrm{Pt}$, with a new cathode catalyst for intermediate temperaturesolid oxide fuel cells (IT-SOFC) $\left(500^{\circ} \mathrm{C}<\mathrm{T}\right)$ range but research has become inadequate. Since Pt sources are limited and very expensive, they could not meet the supply for the commercial fuel cells, the scientists started for searching new materials. There are two important aspects about SOFC cathodes, different cathode materials effect on the electrode electrochemical performance and the oxygen reduction reaction (ORR) kinetics. Understanding in these concepts would lead to improvements of SOFC systems. The production of novel and supreme cathode electrodes used in IT-SOFC is aimed to employ cheaper metals ( $\mathrm{Fe}, \mathrm{Co}, \mathrm{Cr}, \mathrm{Mn}, \mathrm{Gd}$, and $\mathrm{V}$ ) by using superior properties of perovskite structure. The reduction of oxygen on metal oxide surface is achieved within the complicated mechanism. The completion of these steps depends on the nature of oxide ion carrier in cathode, atomic formation in crystal structure, and microstructure of cathode materials. The analysis of the impedances required the use of three to four (RQ) circuits in series in the equivalent circuit model. Of the four cathodes synthesized, the vanadium doped cathode on YSZ showed the highest area specific resistance.

Keywords: Cathodes, Intermediate Temperature-Solid Oxide Fuel Cells (IT-SOFC), Oxygen Reduction Reaction (ORR), Perovskite Structure, Goldschmidt Tolerance Factor.

Submitted: May 16, 2018. Accepted: September 20, 2018.

Cite this: Kısa A, Demircan O. Transition Metal Doped Solid Oxide Fuel Cell Cathodes. JOTCSA. 2018;5(3):1153-68.

DOI: http://dx.doi.org/10.18596/jotcsa.424226.

*Corresponding author. Oktay Demircan, email: oktay.demircan@boun.edu.tr.

\section{INTRODUCTION}

Contemporary attention on building on hydrogen energy and diminishing the ecological pollution has propelled the research on fuel cell innovation, especially, in the area of solid oxide fuel cells (SOFCs) (1). SOFCs, as an electrochemical energy production device, have noteworthy benefits over the ordinary power generation technologies. They are electrochemical systems that transform chemical energy into useful electrical energy with better efficiency because their effectiveness is independent from Carnot cycle of a heat engine (2). Additional efficiency can be achieved when the generated energy is utilized with joint heat and power, or gas turbines (3).
Among the several types of fuel cells, SOFCs own several attractive features, such as better energy conversion efficiency, multiple fuel flexibility, solid-state parts, low greenhouse gas emissions, high power density, environmental friendliness, and lower system noise (4). Similar to other fuel cells, SOFC systems comprises of an electrolyte and the electrodes (anode and cathode). The anode side of the cell is fed with the fuel, e.g. hydrogen and an oxidant such as air is flowed over the cathode side, whereas the electrolyte transfers the oxide ions from cathode to anode or vice versa.

Baur and Preis in 1937 developed the very first SOFC that operated at $1000{ }^{\circ} \mathrm{C}$ (5). Although several decades have passed since their introduction, commonly used SOFCs still work at higher temperatures $\left(\sim 900{ }^{\circ} \mathrm{C}\right)(6,7)$. This 
causes to material deterioration and consequences in higher costs, hence delaying their economic feasibility. Thus, lowering their operation temperature to intermediate range $\left(<800^{\circ} \mathrm{C}\right)$ can diminish the cost and expand life time (8).

Furthermore, high working temperatures limits the choice of materials used in the SOFCs, since deterioration during process will limit the life span of SOFC (9). An obvious site of degradation is air electrode where reduction of oxygen (ORR) occurs, which is generally the key rate limiting step for the functioning of the entire SOFC structure (10). Hence, one of the most important goals in the area of SOFCs is development of new cathode materials that offer a desired electrochemical performance at intermediate temperature range $\left(600-800{ }^{\circ} \mathrm{C}\right)(11)$. Required attributes for such cathode materials are high electronic and ionic conductivity, thermal expansion coefficient values similar to other SOFC compartments, large triple phase boundary (TPB) area, high performance of the catalyst for the dissociation of oxygen, and low cathode resistance (12). Most of these requirements are met by mixed ionic and electronic conductors (MIEC) and their composites. These materials provide synchronized transport of both electrons and ions, hence enhancing the potential reaction sites at the triple phase boundaries, at which the active side of the electrode, the electrolyte and the gases meet. Mixed ionic and electronic conductors generally derive their distinctive properties form their special crystal structure, often referred to as the perovskite structure. The perfect oxide perovskite structure $\mathrm{ABO}_{3}$ contains a cubic array of corner sharing $\mathrm{BO}_{6}$ octahedral with the $A$ cation at the body center location. However, imperfect matching between $A$ and $B$ ionic radii create alterations in the cubic lattice (often rhombohedral or orthorhombic),(13) and these intrinsic alterations leads to vacancies at lattice crystal that exhibit ionic conductivity (14).

Perovskite materials such as $\mathrm{La}_{1-x} \mathrm{Sr}_{x} \mathrm{MnO}_{3-\delta}$ (LSM) with $\mathrm{x}$ between 0.15 and 0.50 are the most commonly used and studied cathode material for standard SOFC (15). These Sr-doped lanthanum perovskites stay stable both in excess-oxidizing and deficient-reducing of oxygen (16). Oxygen deficiency leads to oxygen deficiencies while oxygen-excess results in metal deficient sites, which improves electrode properties. However, the ionic conductivity of LSM is extremely low due to low concentration of oxide ion vacancies (17). This causes useful limitations and restraints to the function of LSM particularly at intermediate temperatures $\left(<800{ }^{\circ} \mathrm{C}\right)$. As the working temperature of SOFC system lowers below 800 ${ }^{\circ} \mathrm{C}$, the oxide ion conductivity for the traditional cathode materials like LSM, in that case distresses the oxygen reduction reaction performance (18). Therefore, incorporation of a material or doping with another metal with comparable higher oxide ion conductivity may ripen the cathode performance.

The study concerned a comparison is made between four different cathode materials under identical conditions. The cathodes investigated LV05SC $\quad\left(\mathrm{La}_{0.595} \mathrm{~V}_{0.005} \mathrm{Sr}_{0.4} \mathrm{CoO}_{3-\delta}\right) \quad$ LV3SF $\left(\mathrm{La}_{0.57} \mathrm{~V}_{0.03} \mathrm{Sr}_{0.4} \mathrm{FeO}_{3-\delta}\right), \quad$ and LV05SM ( $\mathrm{La}_{0.595} \mathrm{~V}_{0.005} \mathrm{Sr}_{0.4} \mathrm{MnO}_{3-\delta}$ ) were successfully synthesized by sol-gel process and are characterized with XRD (X-Ray Diffraction) and XPS (X-Ray Photoelectron Spectroscopy). For electrical conductivity measurements, four-probe conductivity method was performed. Also, for the electrochemical characterization of the electrodes impedance measurements were completed. Of the four cathodes, the LV05SC on YSZ showed the highest area specific resistance. The results for other cathode materials were in good agreement with literature.

\section{EXPERIMENTAL SECTION}

\section{Synthesis and characterizations of cathode materials}

The cathode materials were synthesized by employing a sol-gel method. Figure 1 displays the flow sheet for the synthesis of $\mathrm{La}_{0.6-\mathrm{x}} \mathrm{V}_{\mathrm{x}} \mathrm{Sr}_{0.4} \mathrm{MnO}_{3-\delta}\left(\mathrm{LV}_{\mathrm{x}} \mathrm{SM}, \mathrm{x}=0.005-0.1\right)$ as an example of cathode material by sol-gel process. $\mathrm{La}, \mathrm{Sr}$ and $\mathrm{Mn}$ nitrates and $\mathrm{V}$ acetate (purity $>99.9 \%$, Aldrich Chemicals, USA) were employed as reagents. 


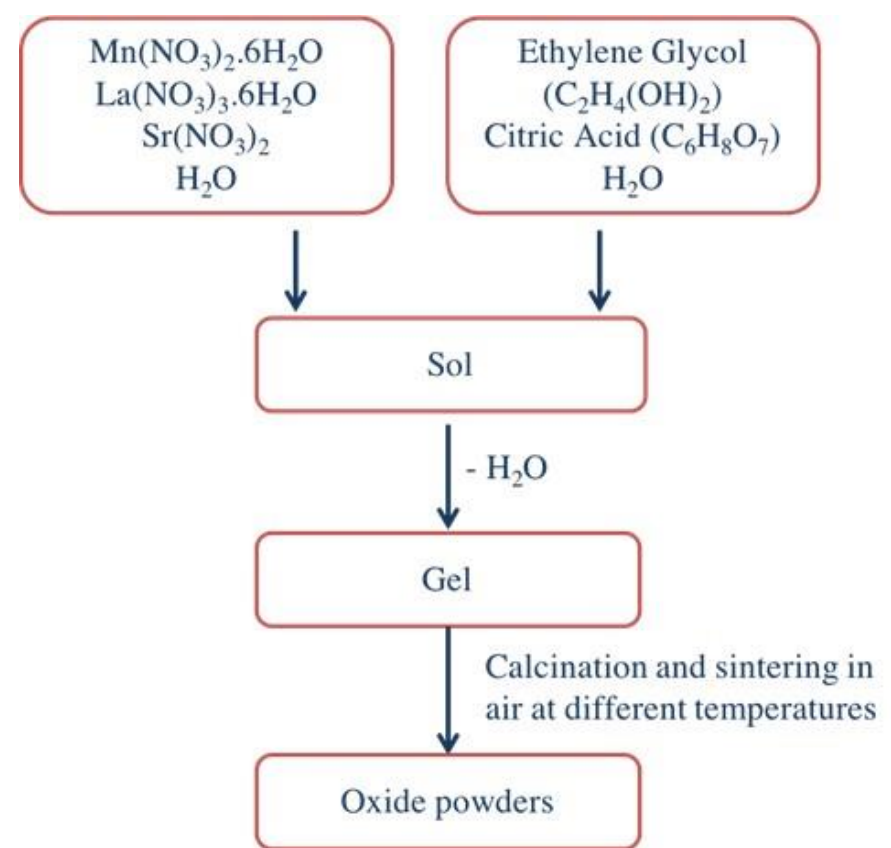

Figure. 1. The preparation of $\mathrm{La}_{0.595} \mathrm{~V}_{0.005} \mathrm{Sr}_{0.4} \mathrm{MnO}_{3-\delta}$ cathode powders by sol-gel process.

All of the reagents, in requisite stoichiometric ratio, were dissolved in the distilled deionized water in a separate manner. Thereafter, all the solutions were mixed together and stirred to obtain a homogeneous solution. After their complete dissolution, a certain amount of citric acid and ethylene glycol were introduced as polymerization and complexation agents, correspondingly.

The molar ratio of citric acid/total metal ions was kept as $1: 2: 1$. The solution was evaporated on a hot plate using a magnetic stirrer until a chocolate-colored gel was formed. When the heating was continued further, the gel completely burns to yield a light and fragile ash. After this mild heating induced gelation, the resulting gel was held in a drying oven at $400{ }^{\circ} \mathrm{C}$ for $2 \mathrm{~h}$ to remove organics and sintered at 900 and $1100{ }^{\circ} \mathrm{C}$ for $3 \mathrm{~h}$ to obtain the perovskite compounds with sufficient crystallinity, as confirmed by X-ray diffraction analysis. The $\mathrm{X}$-ray powder diffraction data (crystal structure and phase composition of the synthesized powders) were collected on a Rigaku D/MAX-Ultima+/PC Diffractometer using $\mathrm{Cu}-\mathrm{Ka}$ radiation $(\lambda=1.54056 \AA)$. The data obtained was compared with reference data for identification of the crystal structure. The morphology of the surface and cross-section of the sintered symmetric cells were examined by scanning electron microscope (ESEM-FEG, Philips $\mathrm{XL} 30$ ) at a potential of $10 \mathrm{kV}$.

The XPS experiments were performed using a Thermo Scientific K-Alpha Surface Analysis instrument at room temperature. An Al K Alpha $X$-Ray source was used with a spot size of $400 \mu \mathrm{m}$ and the spectra of powdered samples were recorded with the constant pass energy values at $150 \mathrm{eV}$. The energy step size was set as $0.100 \mathrm{eV}$ and the charge effect was calibrated using the BE of C1s (284.5eV).
Symmetric cell preparation for EIS analysis Symmetrical electrochemical cells for impedance studies were prepared using various cathode materials and yttria-stabilized zirconia (YSZ) electrolyte. The electrolyte pellets were prepared by pressing commercial powders in a cylindrical stainless-steel mold $(5 \mathrm{~mm}$ in diameter and a thickness of about $0.5 \mathrm{~mm}$ ) with a uniaxial dry press at a pressure of $400 \mathrm{MPa}$. After that, the prepared electrolyte disks were initially calcined at $400{ }^{\circ} \mathrm{C}$ for $2 \mathrm{~h}$ and followed by sintering at $1300^{\circ} \mathrm{C}$ for $2 \mathrm{~h}$. For symmetrical cells, cathode samples were mixed thoroughly with organic binder (Polyvinylbutyral (PVB)) to make the cathodic slurry. The paste obtained was painted on both sides of the pellets with dimensions of 2 $\times 2 \mathrm{~mm}$ by using masking tape. The symmetrical cell was then dried at $150^{\circ} \mathrm{C}$ for $1 \mathrm{~h}$ and sintered at $1300^{\circ} \mathrm{C}$ for $1 \mathrm{~h}$ in air to form porous electrodes well adhered to the electrolytes. The final active area of each cathode was about $0.04 \mathrm{~cm}^{2}$. Finally, the cathodes were connected with $\mathrm{Au}$ paint and wire as current collectors. The symmetrical cells were assembled into a lab-designed setup that allows performing the experiments in different atmospheres. To determine the resistance of the various cathode processes, the manufactured symmetric cells were characterized by EIS measurements in ambient air from 400 to $700{ }^{\circ} \mathrm{C}$ with an increment of $50{ }^{\circ} \mathrm{C}$. $\mathrm{O}_{2}$ concentrations (\% $\mathrm{O}_{2}$ ) around the cell during the measurements were maintained using electronic mass flow controllers and nitrogen was used as the carrier gas. Impedance spectra were measured in the frequency range of $0.1 \mathrm{~Hz}$ to $1 \mathrm{MHz}$ with $10 \mathrm{mV}$ amplitude of the AC signal. The spectra were analyzed using GAMRY Interface 1000 Potentiostat/ Galvanostat, which was interfaced with a computer-controlled program for data acquisition. 


\section{Electrical conductivity measurements} Electrical conductivity of materials was measured as a function of temperature by the standard DC four-terminal method. The conductivity measurements were performed in air on sintered rectangular bars of approximate dimensions $20 \times$ $5 \times 2 \mathrm{~mm}$. Electrical contacts using Au wires (0.25 $\mathrm{mm}$ in diameter, Alfa Aesar) and $\mathrm{Au}$ conductor paste (Heraeus) were placed onto the edges of the sample ensuring a homogeneous current flow. Voltage contacts were prepared as small as possible to prevent any disturbance of the contacts on the current flow. Measurements were performed from 400 to $800{ }^{\circ} \mathrm{C}$ with an interval of $50{ }^{\circ} \mathrm{C}$. The conductivity $(\sigma)$ was determined from a set of $\mathrm{V}-\mathrm{I}$ values by taking $\sigma=1 / \rho=L / A \times d I / d V$, where $L$ is the distance between voltage contacts and $A$ is the sample cross-section.

\section{RESULTS and DISCUSSION}

\section{X-Ray Diffraction (XRD) Results}

Through the primary phase of SOFC progress, platinum and other noble metals were employed as cathodic supplies. Nonetheless, the observations suggest that by enlarging effective area at which chemical steps happen as well as extending the electrochemical boundary including the complete electrode/electrolyte contact area (not only TPB) could elaborate the transport mechanism of electro-active species from the top to the majority of the electrode material. Some of the metal oxides, other than being better $\mathrm{O}_{2}$ catalysts and conductors, demonstrate vital ionic conduction while remaining comparatively stable at running conditions. The bulk appears to play a significant role in determining the electrode kinetics for these mixed conductors (materials conducting both oxide ions and electrons). Hence, these materials deliver another useful key factor to consider when inferring to more multifaceted materials such as perovskites. The very first perovskite materials considered was $\mathrm{La}_{1}$ ${ }_{x} \mathrm{Sr}_{x} \mathrm{CoO}_{3-\delta}$ (LSC) which is now one of the wellknown mixed conductors and it was trailed quickly afterwards by a number of other materials with perovskite crystal structure, including $\mathrm{La}_{1}$ ${ }_{x} \mathrm{Sr}_{x} \mathrm{MnO}_{3-\delta}$ (LSM), which has developed the favored material for SOFC cathodes.

Ideal perovskite crystallizes in cubic close-packed lattice structure. The structure and purity of the crystal samples were determined by XRD. As previously stated $\mathrm{LV}_{\mathrm{x}} \mathrm{SC}\left(\mathrm{La}_{0.6-\mathrm{x}} \mathrm{V}_{\mathrm{x}} \mathrm{Sr}_{0.4} \mathrm{CoO}_{3-\delta}\right)$ (x $=0.005,0.01,0.02,0.03,0.04,0.05,0.10)$ examples were synthesized by a sol-gel method after calcination at $1100{ }^{\circ} \mathrm{C}$ with open air for $2 \mathrm{~h}$. Figure 2 displays the XRD configurations of the resulting LV05SC $\left(\mathrm{La}_{0.595} \mathrm{~V}_{0.005} \mathrm{Sr}_{0.4} \mathrm{CoO}_{3-\delta}\right)$ crystals measured at room temperature.

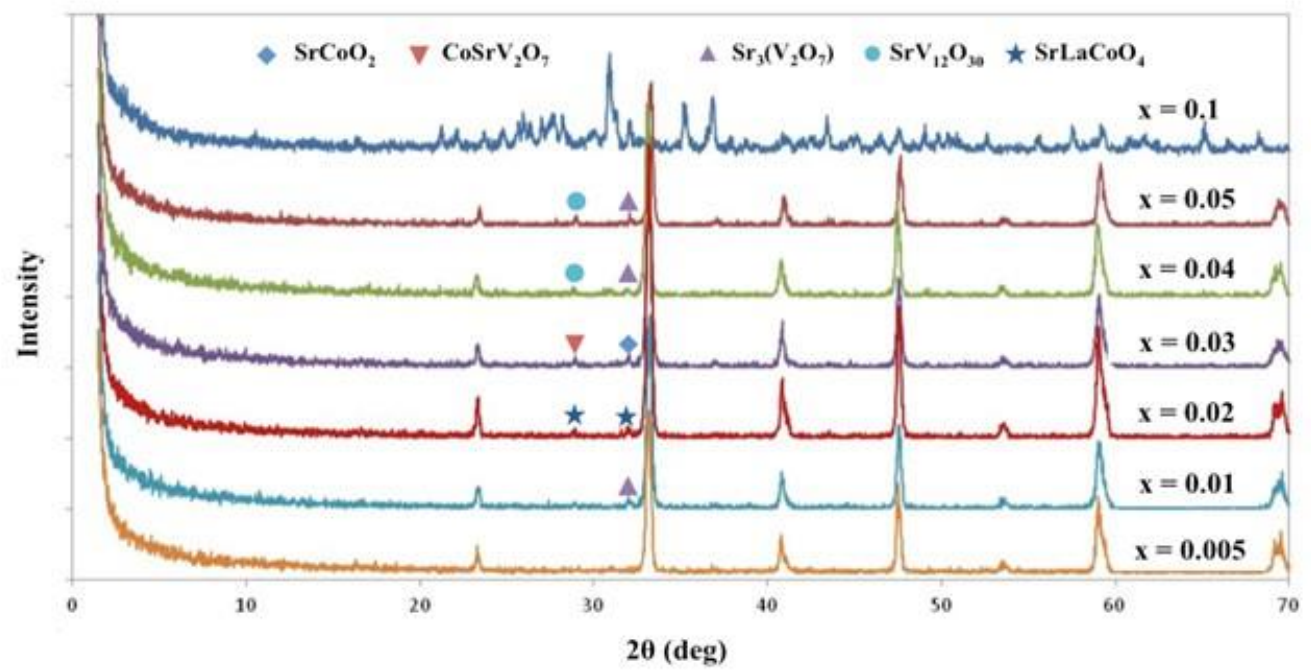

Figure 2. XRD patterns of LV05SC $\left(\mathrm{La}_{0.6-\mathrm{x}} \mathrm{V}_{\mathrm{x}} \mathrm{Sr}_{0.4} \mathrm{CoO}_{3-\delta}\right)(\mathrm{x}=0.005-0.1)$ material sintered at $1100{ }^{\circ} \mathrm{C}$ in air for $2 \mathrm{~h}$.

It is deduced that the crystals with vanadium portions of $x \leq 0.005$ exhibit an evidently defined perovskite structure with a single-phase. Nevertheless, when the doping ratio of vanadium was additional increased $(x \geq 0.01)$ other phases like different kinds of oxides could be observed in the LV05SC ( $\mathrm{La}_{0.595} \mathrm{~V}_{0.005} \mathrm{Sr}_{0.4} \mathrm{CoO}_{3-\delta}$ ) samples. For example, as seen in the above figure for LV10SC sample, two impurities were identified as $\mathrm{Sr}_{3} \mathrm{~V}_{2} \mathrm{O}_{8}$ and $\mathrm{SrVO}_{3}$. This implies that the edge of $\mathrm{V}$ doping in these sequences of LVxSC materials would not be more than $0.5 \mathrm{~mol} \%$. With rising $\mathrm{V}$ content, the diffraction patterns of LVxSC moved slightly to higher angle direction, as can be deduced clearly from Figure 2, representing the reduction of crystal parameters. A cubic perovskite series of LVXSC materials were prepared and the effect of $V$ content on the lattice structure was considered in relation to their possible employment as cathode materials for SOFC. The solid content limit of $V$ in LV05SC $\left(\mathrm{La}_{0.595} \mathrm{~V}_{0.005} \mathrm{Sr}_{0.4} \mathrm{CoO}_{3-\delta}\right)$ is almost $\mathrm{x}=0.005$ at $1100^{\circ} \mathrm{C}$. As the cubic structure crystallinity of LV05SC $\left(\mathrm{La}_{0.595} \mathrm{~V}_{0.005} \mathrm{Sr}_{0.4} \mathrm{CoO}_{3-\delta}\right)$ materials decreases with V-doping level, LV05SC ( $\left.\mathrm{La}_{0.595} \mathrm{~V}_{0.005} \mathrm{Sr}_{0.4} \mathrm{CoO}_{3-\delta}\right)$ 
was selected as the candidate cathode material on emphasis.

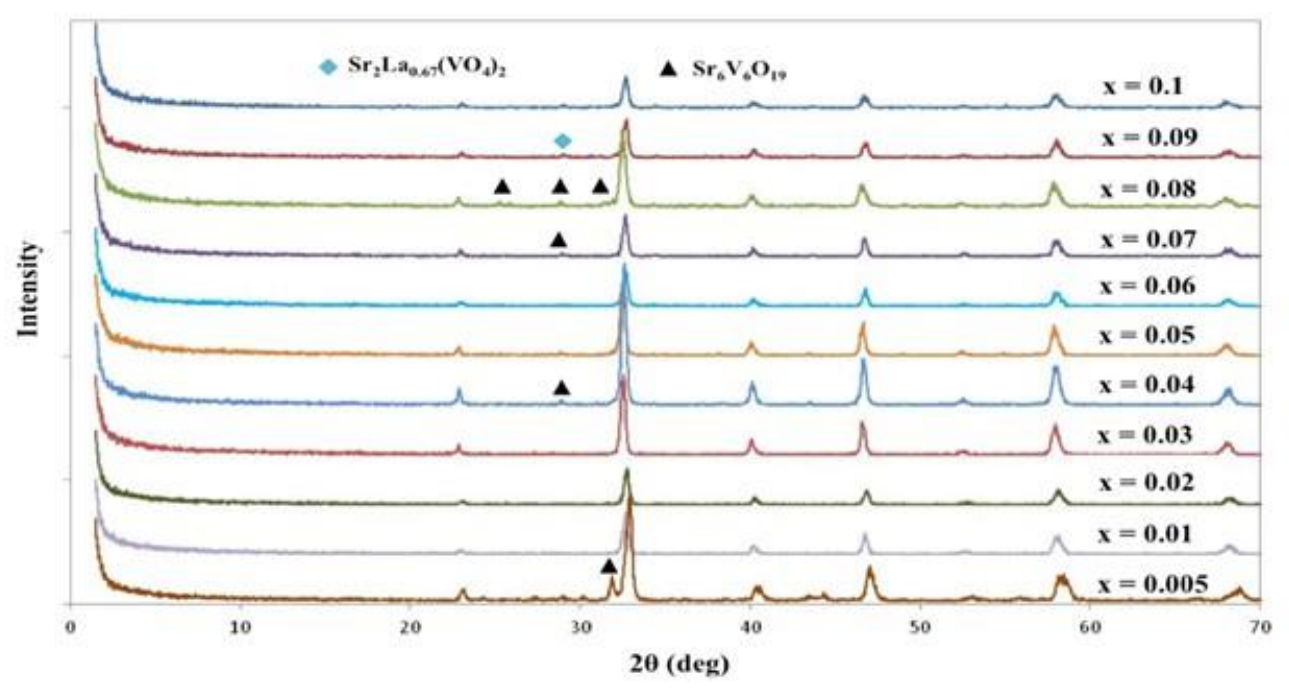

Figure 3. XRD patterns of the as-synthesized LVxSF $\left(\operatorname{La}_{0.6-x} \mathrm{~V}_{x} \mathrm{Sr}_{0.4} \mathrm{FeO}_{3-\delta}\right),(x=0.005-0.1)$ material sintered at $1100^{\circ} \mathrm{C}$ in air for $2 \mathrm{~h}$.

Figure 3 shows the XRD patterns of the assynthesized LVxSF $\left(\mathrm{La}_{0.6-\mathrm{x}} \mathrm{V}_{\mathrm{x}} \mathrm{Sr}_{0.4} \mathrm{FeO}_{3-\delta}\right),(\mathrm{x}=$ 0.005 - 0.1), abbreviated as LVxSF correlated with the vanadium content hereafter. All compositions exhibit a perovskite structure, which is either orthorhombic or rhombohedral, and no extra phase appears. This implies that fractional exchange of $V$ for La has no effect on the growth of layered perovskite phase. The slightly diverse structure change in this case is because of ionic radii and the introduction of $\mathrm{V}^{3+}$ ions. However, it can be seen that all samples were nearly phase pure, but for the nominal LV3SF (which is $\mathrm{La}_{0.57} \mathrm{~V}_{0.03} \mathrm{Sr}_{0.4} \mathrm{FeO}_{3-\delta}$ for $\mathrm{x}=0.03$ ) sample, a second phase marked with $\boldsymbol{\Delta}$ was observed. As indicated in Figure 3, the second phase can be indexed to Strontium Vanadium Oxide, $\mathrm{Sr}_{6} \mathrm{~V}_{6} \mathrm{O}_{19}$. This result emphasizes the solid solution limit of $\mathrm{V}$ in $\mathrm{La}_{0.57} \mathrm{~V}_{0.03} \mathrm{Sr}_{0.4} \mathrm{FeO}_{3-\delta}$ is greater than $0.5 \%$. As the LV4SF samples showed a second phase as evidenced by additional peaks at $2 \theta$ value of $29.8^{\circ}$, even though the phase was not unambiguously identified but closely matched that of $\mathrm{Sr}_{6} \mathrm{~V}_{6} \mathrm{O}_{19}$, LV3SF $\left(\mathrm{La}_{0.57} \mathrm{~V}_{0.03} \mathrm{Sr}_{0.4} \mathrm{FeO}_{3-\delta}\right)$ was selected as the candidate cathode material on consideration due to its single-phase crystallinity and relatively high peak intensity among others.

Phase homogeneity of $\mathrm{La}_{0.6-\mathrm{x}} \mathrm{V}_{\mathrm{x}} \mathrm{Sr}_{0.4} \mathrm{MnO}_{3-\delta}(\mathrm{x}=$ 0.005 - 0.1) was compared as in Figure 4 by XRD analysis. $\mathrm{La}_{0.6-\mathrm{x}} \mathrm{V}_{\mathrm{x}} \mathrm{Sr}_{0.4} \mathrm{MnO}_{3-\delta}$ like all the $\mathrm{La}_{1-}$ ${ }_{x} \mathrm{Sr}_{x} \mathrm{MnO}_{3}$ materials develops in a rhombohedral structure. The rhombohedral development of the perfect perovskite octahedron is described by the split of the major reflection, in which performs as two peaks in between $32^{\circ}$ and $33^{\circ}$.

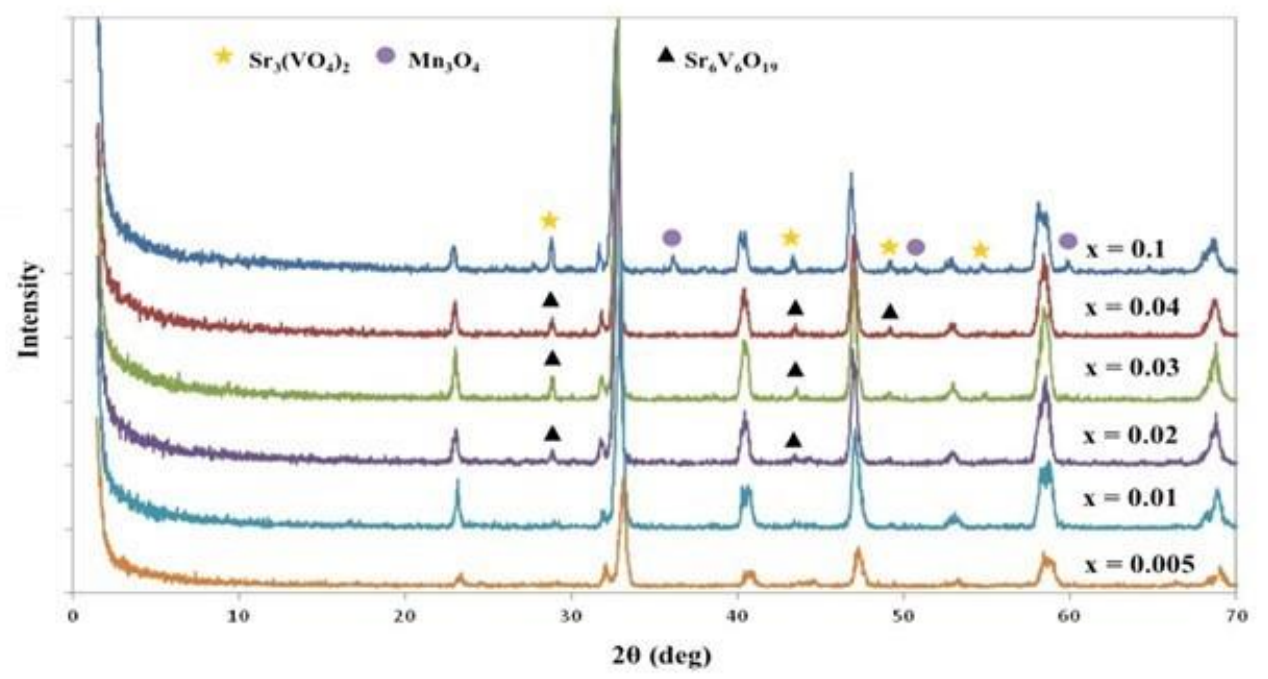

Figure 4. $X R D$ patterns of the as-synthesized $L_{0.6-x} \mathrm{~V}_{x} \mathrm{Sr}_{0.4} \mathrm{MnO}_{3-\delta}(x=0.005-0.1)$ material sintered at $1100{ }^{\circ} \mathrm{C}$ in air for $2 \mathrm{~h}$. 
Figure 4 presents typical XRD patterns of La 0.6 ${ }_{x} \mathrm{~V}_{\mathrm{x}} \mathrm{Sr}_{0.4} \mathrm{MnO}_{3-\delta}(\mathrm{x}=0.005-0.1)$ fired exactly at $1100^{\circ} \mathrm{C}$. The patterns suggest that the LVxSM samples have the only phase of perovskite structure with no extra impurities till $x=0.01$ and $\mathrm{Sr}_{6} \mathrm{~V}_{6} \mathrm{O}_{19}$ secondary phase at $29.6^{\circ}$ observed with $\mathrm{V}$ ratio above $x=0.01$. This shows that $\mathrm{LVxSM}$ can crystallize with a perovskite structure under the $V$ percent of $x \leq 0.01$. No extra phases, either $\mathrm{La}_{2} \mathrm{Zr}_{2} \mathrm{O}_{7}$ or $\mathrm{SrZrO}_{3}$, are observed by XRD for the LV10SM cathode material. $A$ well-defined perovskite phase can be perceived from Figure 4. Nevertheless, there can be seen some impurity patterns as small peaks in XRD. It is found that these belong to $\mathrm{Sr}_{3}\left(\mathrm{VO}_{4}\right)_{2}$ by XRD phase analysis software. This impurity as $\mathrm{Sr}_{3}\left(\mathrm{VO}_{4}\right)_{2}$ is the perovskite type of structure associated with mixed ionic-electronic conductor, and this phase is not recognized as detrimental to the SOFC cathode. However, it is obvious that the perovskite crystallinity distorted as seen. It recommends that the limit of $\mathrm{V}$ content in La.6${ }_{x} \mathrm{~V}_{\mathrm{x}} \mathrm{Sr}_{0.4} \mathrm{MnO}_{3-\delta}(\mathrm{x}=0.005-0.1)$ systems would not be exceeding of $10 \mathrm{~mol} \%$. The diffraction pattern confirms the pure rhombohedral phases of LV05SM ( $\mathrm{La}_{0.595} \mathrm{~V}_{0.005} \mathrm{Sr}_{0.4} \mathrm{MnO}_{3-\delta}, \mathrm{x}=0.005$ ) and replacement of $\mathrm{V}$ at a range of $0.5 \mathrm{~mol} \%$ would not change the crystallinity of the structure, thus LV05SM had possible claim as a cathode material.

\section{X-Ray Photoelectron Spectroscopy (XPS) Results}

The main function of the cathode material in SOFC can be described as contributing reaction spots for oxygen reduction reaction (ORR). Hence, in order to address the reaction mechanisms and processes in ORR, the description of the activity on the site of materials for ORR is vital. The properties of electrocatalysts and ion transport of the cathode samples mostly depend on the oxygen diffusion and adsorption. The degree of the reaction, which oxygen is first land on from the atmospheric environment, relies greatly on the composition and structure of the outmost oxides' surface. The structure and the composition of oxide surface can vary from the bulk of the material. Improved characterization of the surface properties of cathode materials is so fundamental. Early studies on cathode samples are mainly centered upon the electrochemical properties (63) and there are few studies done for the view of surface of the sample. In this respect, XPS is an extremely beneficial technique for characterization of these important restrictions as the oxidation state of metals employed, their comparative content and the surface metals' proportion.

XPS survey spectrum of LV05SC (La $0.6-$ $\left.{ }_{x} \mathrm{~V}_{\mathrm{x}} \mathrm{Sr}_{0.4} \mathrm{CoO}_{3-\delta}, \mathrm{x}=0.005\right)$ in Figure 5 shows that the oxidation states of metals in the control and this content of the as-synthesized LV05SC cathode material and the fitted curves about elements within the powder proved that no extra impurity of metals other than La, Co, Sr and V except $\mathrm{C} 1 \mathrm{~s}$ are displayed on whole spectrum.

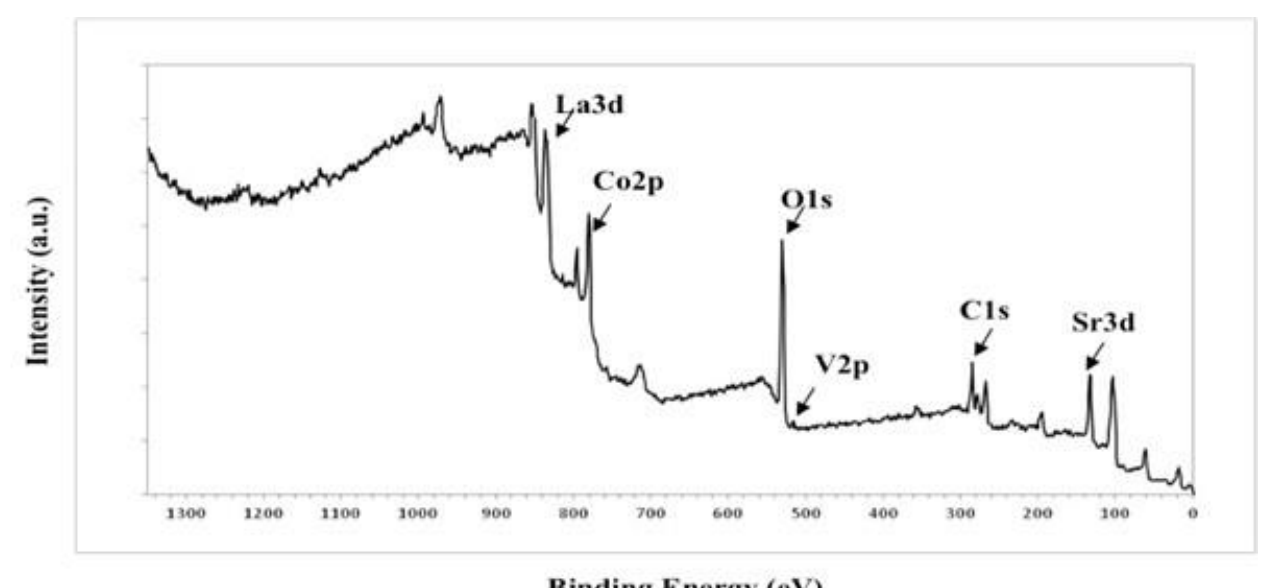

Binding Energy $(\mathrm{eV})$

Figure 5. XPS survey spectrum of the LV05SC material.

The reason for the splitting in the La3d peaks in the XPS is not only because of a spin-orbit type interaction seen as two lines $3 d_{5 / 2}$ and $3 d_{3 / 2}$, furthermore, each line is divided because of a relocation of an electron from oxygen atom to La4f, which is originally empty. As can be seen from the Figure 5, the V2p signal is split into two peaks of $V 2 p_{3 / 2}$ and $V 2 p_{1 / 2}$ seen at binding energies of 515.68 and $517.48 \mathrm{eV}$, ascribed to $\mathrm{V}^{5+}$ and $\mathrm{V}^{4+}$, correspondingly. Therefore, the $\mathrm{V} 2 \mathrm{p}$ core-level spectra further approves that the assynthesized LV05SC sample contains both $\mathrm{V}^{5+}$ and $\mathrm{V}^{4+}$. The Sr3d region in XPS as shown in
Figure 5, contains a doublet, on which the binding energies are 132.8 and $130.98 \mathrm{eV}$ appointed to $\mathrm{Sr}_{3} \mathrm{~d}_{3 / 2}$ and $\mathrm{Sr} 3 \mathrm{~d}_{5 / 2}$ peaks, correspondingly. These values are very similar to compounds considered as the $\mathrm{Sr}^{2+}$ ions in LV05SC. The Co2p XPS region Figure 5 for LV05SC. The peak at $779.58 \mathrm{eV}$ arose from Co2 $\mathrm{p}_{3 / 2}$, and the one with peak at $795 \mathrm{eV}$ was because of $\mathrm{Co} 2 \mathrm{p}_{1 / 2}$. For the Co2p spectrum, a key peak at around $779.58 \mathrm{eV}$ supplemented by a smaller shoulder at around $789.5 \mathrm{eV}$ is existing and this smaller shake-up line displays the existence of $\mathrm{Co}^{3+}$. For the systems containing cobalt, a weak shoulder offering on the 
higher binding energy range of the Co2p3/2 spectrum at roughly $788 \mathrm{eV}$ can be recognized as $\mathrm{Co}^{4+}$.

XPS survey spectrum of LV05SM (La $0.6-$ $\left.{ }_{\mathrm{x}} \mathrm{V}_{\mathrm{x}} \mathrm{Sr}_{0.4} \mathrm{MnO}_{3-\delta}, \mathrm{x}=0.005\right)$ illustrates the chemical nature of $\mathrm{La}, \mathrm{V}, \mathrm{Sr}$, and $\mathrm{Mn}$ ions estimated by fitting of La3d, V2p, Sr3d and V2p spectrum, as shown in Figure 6. No extra metals except La, Mn, $\mathrm{Sr}$ and $\mathrm{V}$ except $\mathrm{C} 1 \mathrm{~s}$ are detected on the whole spectra. The La3d states of LV05SM can be seen in Figure 6. The $\mathrm{La3d}_{3 / 2}$ line is split into two peaks seen at 853.38 and $850.68 \mathrm{eV}$ binding energy values, and the corresponding of $\mathrm{La} 3 \mathrm{~d} 5 / 2$ is 837.3 and $833.5 \mathrm{eV}$.

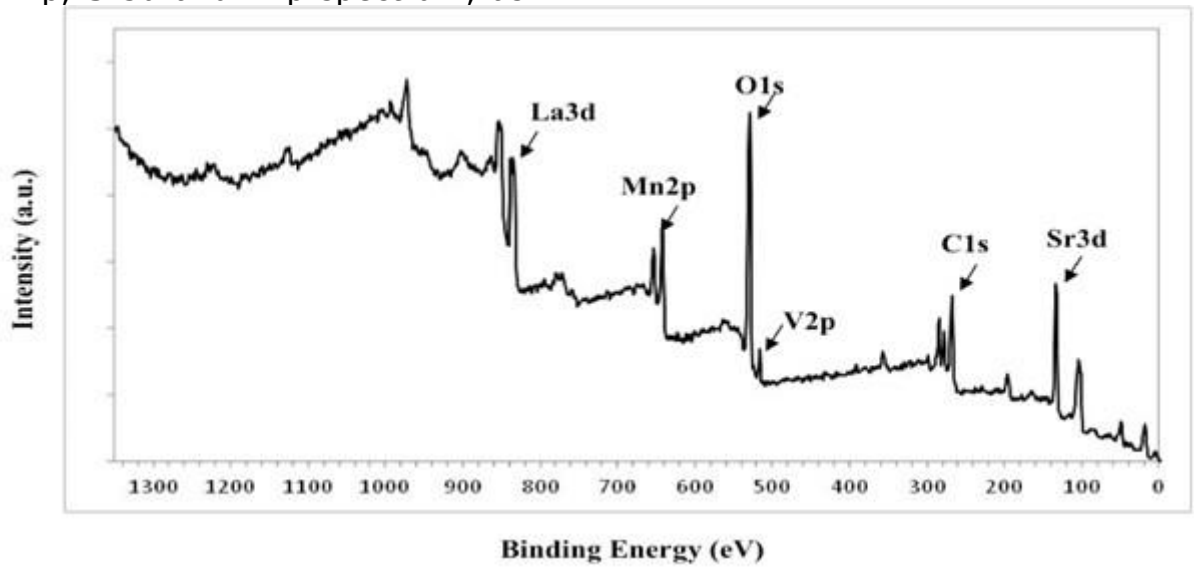

Figure 6. XPS survey spectrum for LV05SM material.

Binding variance in energy level of the $3 \mathrm{~d} 3 / 2$ and $3 \mathrm{~d} 5 / 2$ is almost $17 \mathrm{eV}$. These binding energies and the shape of splitting agrees well with published results for $\mathrm{La}^{3+}$ materials in Figure 6 . The V2p peaks in binding energy levels are 515.88 and $516.6 \mathrm{eV}$ for $\mathrm{V} 2 \mathrm{p}_{3 / 2}$ and $\mathrm{V} 2 \mathrm{p}_{1 / 2}$, correspondingly. Peaks are considered as the states of $\mathrm{V}^{5+}$ and $\mathrm{V}^{3+}$ in XPS analysis. The $\mathrm{Sr} 3 \mathrm{~d}$ spectrum analysis of the LV05SM comprises two peaks as seen in Figure 6 , on which peaks at 132.2 and $133.08 \mathrm{eV}$ are assigned as $\mathrm{Sr}_{3} \mathrm{~d}_{5 / 2}$ and $\mathrm{Sr}_{3} \mathrm{~d}_{3 / 2}$ lines, correspondingly, indicating that these $\mathrm{Sr}$ ions are placed in two different chemical natures. As concerning the XPS analysis of $\mathrm{Sr}_{3} \mathrm{~d}_{5 / 2}$ line, the component at 132.1-132.7 eV originates from $\mathrm{Sr}$ ions united into the structure as perovskite. This peak observed for $\mathrm{Sr}_{3} \mathrm{~d}_{3 / 2}$ may be appointed to $\mathrm{Sr}^{2+}$. From the XP spectra, it is decided that these binding energy values are similar for compounds attributed to the $\mathrm{Sr}^{2+}$ ions in LV05SM. Also, the Mn2p XP spectra of LV05SM in Figure 6 exhibits a wide-ranging emission with a maximum close to $641.2 \mathrm{eV}$ for $\mathrm{Mn} 2 \mathrm{p} 3 / 2$ and 653.08 eV for $M n 2 p_{1 / 2}$ emissions. With respect to the binding energy values of $M n 2 p_{3 / 2}$, the oxidation degrees of $\mathrm{Mn}$ ions are +3 and +4 .

XPS survey spectrum of LV3SF $\left(\mathrm{La}_{0.6-\mathrm{x}} \mathrm{V}_{\mathrm{x}} \mathrm{Sr}_{0.4} \mathrm{FeO}_{3-}\right.$ $\delta, x=0.03$ ) displays the composition of the surface and the valance states of elements in the as-synthesized LV3SF sample as shown in Figure 7 and further investigated by the fitted curves about elements within the powder. Just La, Sr, $\mathrm{Mn}, \mathrm{C}$ and $\mathrm{O}$ elements are detected on the material surface. No extra peaks related to the impurities were observed in XPS analysis.

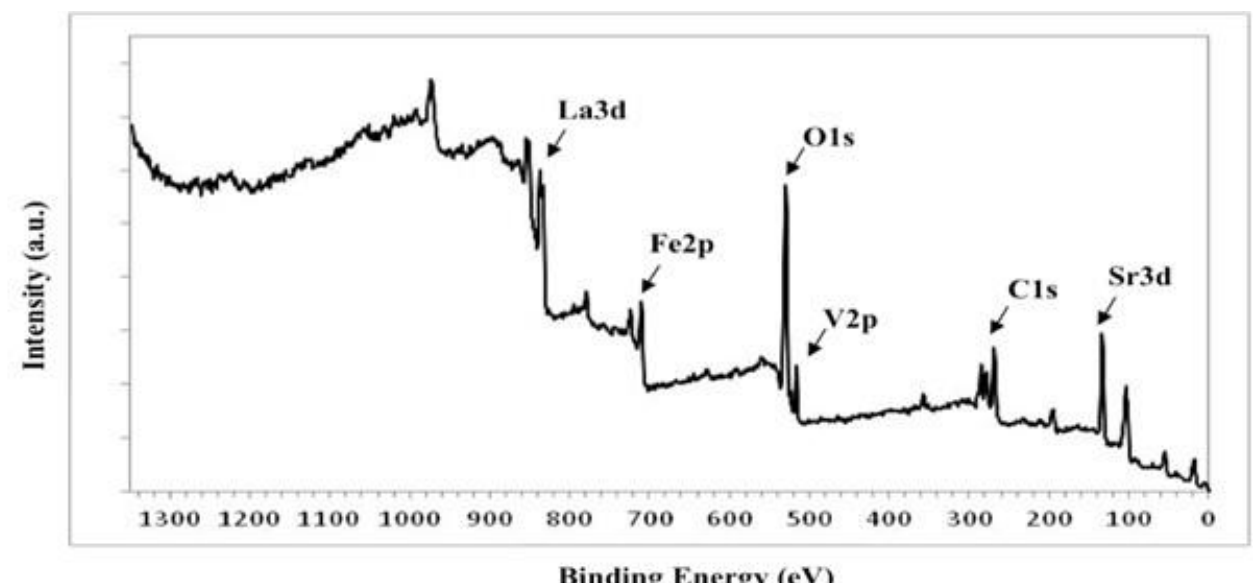

Figure 7. XPS survey spectrum of the LV3SF material.

In Figure 7, the La3d states of LV3SF are shown. In the binding energy region for La, there are two lines, first at $833 \mathrm{eV}$ corresponding to $\mathrm{La}^{3+}$ in perovskite phase and, another at $836 \mathrm{eV}$, corresponding to $\mathrm{La}^{3+}$ in $\mathrm{La}_{2} \mathrm{O}_{3}$. From XPS spectra, it can be judged that only $\mathrm{La}^{3+}$ ions exist in LV3SF sample. The V2p XPS, as shown in Figure 7, contains a broad peak, for which binding energy 
values are 515.98 and $517 \mathrm{eV}$ assigned as $\mathrm{V} 2 \mathrm{p}_{3 / 2}$ and $V 2 p_{1 / 2}$ lines, correspondingly. These are presumed to be $\mathrm{V}$ as $\mathrm{V}^{5+}$ and $\mathrm{V}^{3+}$ states. From the spectra, it can be concluded that vanadium exists in a mixed oxidation state. The chemical state of the Sr element was revealed by XPS (Figure 7). The binding energy for the $S r 3 d_{3 / 2}$ and $S r 3 d_{5 / 2}$ peak of as-prepared LV3SF cathode is $132.8 \mathrm{eV}$ and $131.68 \mathrm{eV}$, respectively, corresponding to $\mathrm{Sr}^{2+}$ in LV3SF and few SrO, because this binding energy value is near to the similar compounds. Figure 7 also displays the asymmetric Fe 2p spectrum of the LV3SF material and two oxidation states, $\mathrm{Fe}^{3+}$ and $\mathrm{Fe}^{4+}$. Two peaks with energy values at 719.5 and $723.3 \mathrm{eV}$ may be ascribed to the $\mathrm{Fe}^{3+} 2 \mathrm{p}_{3 / 2}$ and $2 \mathrm{p}_{1 / 2}$ spectrum, correspondingly. Remarkably, a small shoulder peak at $718.8 \mathrm{eV}$ emerges between the doublet peaks, agreeing to the $\mathrm{Fe}^{4+} 2 \mathrm{p}_{3 / 2}$.

\section{Electrical Conductivity - Four Probe Measurement Results}

The electrical conductivity of as-synthesized materials was characterized by the four-probe direct current (DC) technique on the calcined rectangular bars. These measurements were completed while ramping the temperature between 400 and $800{ }^{\circ} \mathrm{C}$ in open air, and with a temperature ramping rate of $1^{\circ} \mathrm{C} / \mathrm{min}$. Four gold $\mathrm{Au}$ connection wires were placed, which were smeared with gold conductor paste. Two current wires were attached at the bar edges, and two voltage wires in between at a certain distance $l$. The bar was then sintered at $500{ }^{\circ} \mathrm{C}$ for $1 \mathrm{~h}$ to achieve comprehensive connection of the probes and reduction of the connection resistance. The bar was then located horizontally in a tube oven. An electric current in this method is delivered through a bar of the material and a voltage decline is measured across a distance in the middle of the bar. The bar was held at each temperature till measurement completed. The electrical conductivity $\sigma$ was analyzed by the following equation: $\boldsymbol{R}=\boldsymbol{\rho} . \boldsymbol{I} / \boldsymbol{A}$, where $R$ is the polarization resistance, $A$ is the bar crosssectional area, $I$ is the distance between the inner electrodes (either current or voltage), and $\rho$ is the specific resistance. Electrical conductivity $(\sigma)$ parameters were acquired through the converse of the specific resistance. The as-synthesized LV05SC, LV05SM and LV3SF cathode materials were prepared for four-probe DC method and the conductivity value acquired is controlled with reference data for each material.

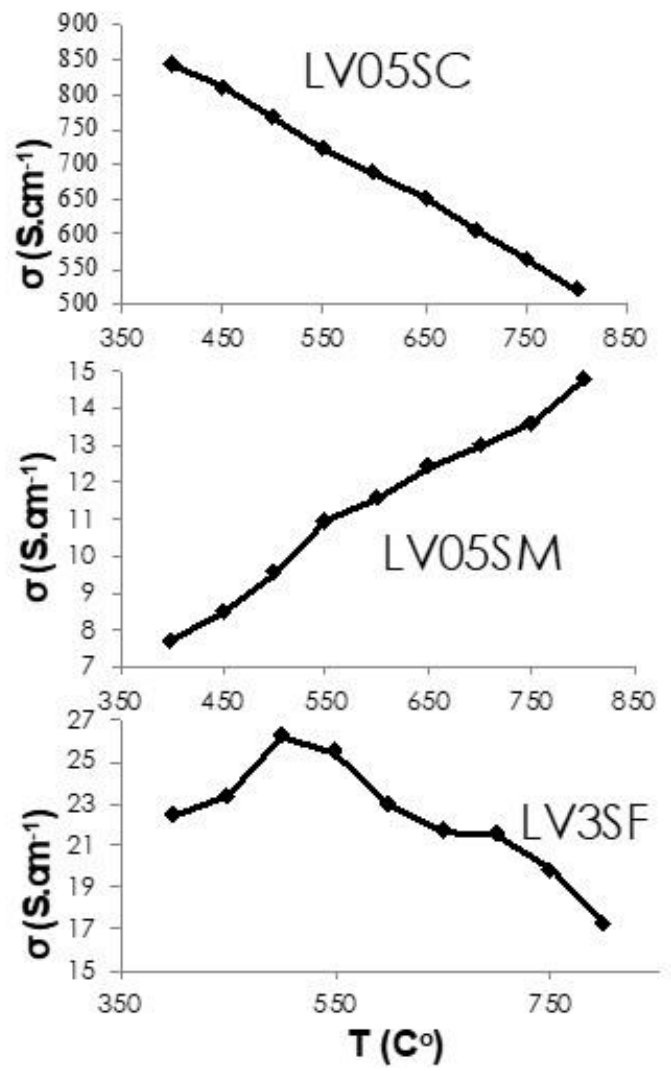

Figure 8. Temperature dependence of the electrical conductivity of LV05SC, LV05SM, and LV3SF sample sintered at $1100^{\circ} \mathrm{C}$.

Electrical conductivity of LV05SC, LV05SM, and LV3SF and its dependence on temperature have been reported for cathode materials shown in Figure 8. A clarification of these ideas is intricate in particular to two main aspects contributed to the electrical conductivity of cathode materials. The distinct parameter of the crystal structure is the first factor due to interatomic distances and angles, on the other hand, as the second factor the charge carrier content is the concentration of electron vacancies. In these kind of metal oxides, oxide ion transport happens through the oxygen deficiencies hopping in the perovskite structure, at which the transfer of the electrons is alongside the way $\mathrm{B}^{\mathrm{n}}-\mathrm{O}-\mathrm{B}^{\mathrm{n}+1}$ as second metal bond owing to overlying between the B-metal $3 \mathrm{~d}$ orbitals and oxygen $2 p$ orbitals.

The highest conductivity for LV05SC achieved to its maximum with $843 \mathrm{~S} / \mathrm{cm}$ around $400{ }^{\circ} \mathrm{C}$ and reduced to $521.50 \mathrm{~S} / \mathrm{cm}$ at $800^{\circ} \mathrm{C}$ in Figure 8 . It reveals the anticipated metal conductivity behavior and it signifies to the reduction in the electron-hole content with rising temperature. The metal conductivity behavior is detected in $\mathrm{La}_{1-x} \mathrm{Sr}_{\mathrm{x}} \mathrm{CoO}_{3}$ cubic phase, whereas the semiconductor performance is scrutinized in the rhombohedral part. When the electrical conductivity decreases with increasing temperature this means metallic behavior, on the hand, as the electrical conductivity increases with temperature, this means semiconducting behavior. 
Four probe electrical conductivity measurements of LV05SM in Figure 8 show that the conductivity of LV05SM material under air was measured using a four-probe DC method. LSM has been acknowledged as a p-type semiconductor with electronic holes as charge carriers and essentially this hole motion in the d-orbitals energy levels of manganese is the reason for the electrical conductivity. This is elucidated by the minor polaron hopping of electron holes between $\mathrm{Mn}^{4+}$ and $\mathrm{Mn}^{3+}$ on octahedral corners. The mechanism of electrical conduction was accomplished by the hopping of electrons between multivalent metal ions at $\mathrm{B}$-site and oxide ion resulting the way along $\mathrm{B}-\mathrm{O}-\mathrm{B}$ bonds. The equilibrium between $\mathrm{Mn}^{4+}$ and $\mathrm{Mn}^{3+}$ ions are controlled by a thermally activated disproportionation of $\mathrm{Mn}^{3+}$ in crystalline solids. $\mathrm{Mn}^{2+}$ ion is formed due to disproportionation but the conduction process occurs just via the carriers hopping amongst $\mathrm{Mn}^{4+}$ and $\mathrm{Mn}^{3+}$ sites. As a result of charge transfer from $\mathrm{Mn}^{3+}$ site to neighboring $\mathrm{Mn}^{4+}$ site, the conduction process is assumed to develop, such as jumps of p-type carriers over available sites. Since the electronic conductivity is typically $100-1000$ times higher than the ionic conductivity for these kinds of oxides, the measured values reported herein are attributed to the electronic conductivity only. Generally, the electrical conductivity gradually rises with increasing temperature. However, there is a variation in conductivity at around $550{ }^{\circ} \mathrm{C}$, which can be attributed to the loss of the lattice oxygen resulting to more oxygen vacancies because of the thermally stimulated lattice oxygen losses. However, the lattice oxygen loss in p-type semiconductors at higher temperatures could be the reason for the decline of electrical conductivity, because of the decrease of charge carrier content (electron holes). There is only electrical conductivity variation at around $550^{\circ} \mathrm{C}$ and no stable fall of conductivity is detected in the temperature between $400{ }^{\circ} \mathrm{C}$ and $800{ }^{\circ} \mathrm{C}$. This means that there is a slight lattice oxygen decrease and hence comparatively well structural stability of LV05SM.

Electrical conductivity analysis of LV3SF seen in Figure 8 pointed that the sample must acquire the higher electrical conductivity at the desired working temperatures meanwhile the lower electrical conductivity can consequence in a reduced current-collecting effectiveness and the higher ohmic resistance of cathode material. Values of complete mixed conductivity parameter include both electronic and ionic conductivity values because of the existence of charge carriers and oxygen vacancies, correspondingly. Nevertheless, ionic conductivity in perovskite structure is recognized to be slight in judgement with the complete conductivity. Hence, the experimentally calculated values of the electrical conductivity are expected to be contributor to the electronic conductivity only. The conductivity ascents gradually with rising temperature, achieves the maximum value of $26.23 \mathrm{~S} / \mathrm{cm}$ at almost $500{ }^{\circ} \mathrm{C}$ and then falls with additional temperature increase. It may be elucidated as the electrical conductivity in Sr-doped $\mathrm{LaFeO}_{3}$ is commonly considered to appear by the lattice oxygen loss, implying a semiconductor behavior, related with the tetravalent state of the $\mathrm{Fe}$ cations. The decrease in the conductivity at high temperatures is essentially because of the oxygen vacancies formation, complemented by reduction of $\mathrm{Fe}^{4+}$ to $\mathrm{Fe}^{3+}$ that consequences in a decrease of the charge carrier content.

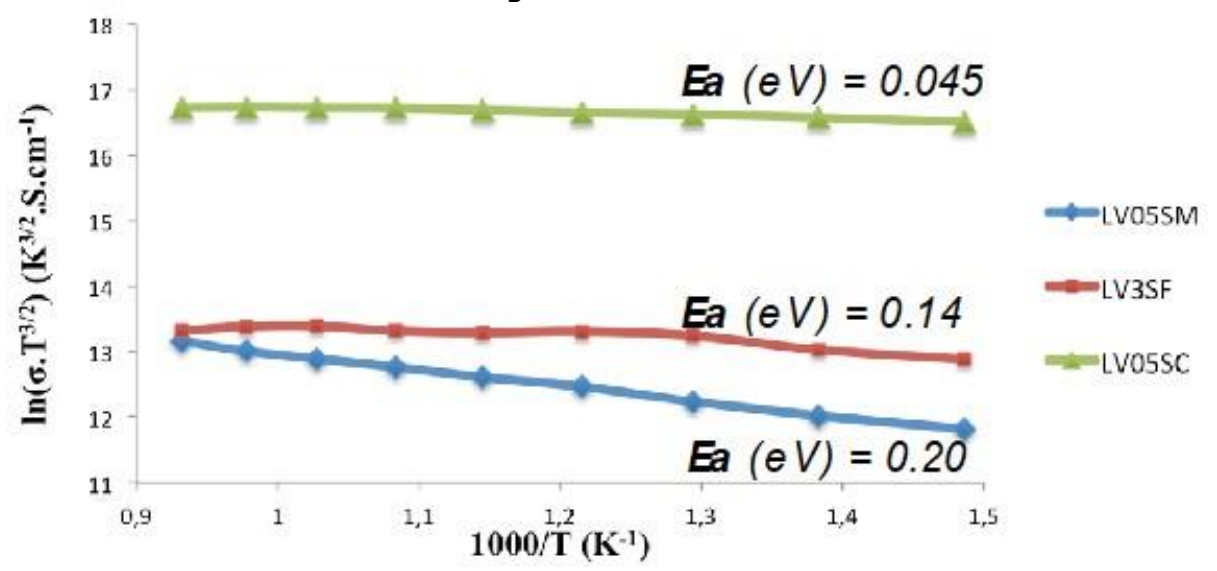

Figure 9. Activation energy $\left(E_{a}\right)$ of LV05SC, LV05SM, and LV3SF measured over $400-800{ }^{\circ} \mathrm{C}$.

The logarithm of electrical conductivity of LV05SC, LV05SM, and LV3SF measured while increasing temperature from 400 to $800{ }^{\circ} \mathrm{C}$ in open air and the electrical conductivity of sample are calculated as a temperature function in Figure 9. The temperature dependence of electrical conductivity is shown in Figure 9 summarizes the $E_{a}$ values for LV05SC, LV05SM, and LV3SF. It was calculated as $0.045 \mathrm{eV}$ for LV05SC, $0.20 \mathrm{eV}$ for LV05SM, and $0.14 \mathrm{eV}$ for LV3SF.

The dependency of electrical conductivity on temperature is generally given as:

$$
\sigma=\left(\frac{A}{k T^{s}}\right) \exp \left(-\frac{E_{a}}{k T}\right)
$$


in which $k$ is the Boltzmann constant, $E_{a}$ is the activation energy for electrical conductivity, $T$ is the absolute temperature and $A$ is the preexponential parameter that covers a number of constants such as the number of charge carriers and the standard distance between the B- site ions. The part of $s$ is accepted as either 1 or $3 / 2$ for an adiabatic or non-adiabatic hopping manner, correspondingly. The graph of In $\sigma . T^{\mathrm{S}} \mathrm{vs}$. $1000 / T$ would provide a straight line. The plot of synthesized sample direct fit was achieved for $\mathrm{s}$ $=3 / 2$, signifying a non-adiabatic hopping manner, seen in Figure 9.

\section{Electrochemical Impedance Spectroscopy Results}

The results from Four Probe Method measurements show that the conductivity values are lower than expected. However, there are more important expectations than the electrical conductivity like the ionic one, which is one of the main features of the cathode performance for SOFC. The most complex and least understood

$400^{\circ} \mathrm{C}$

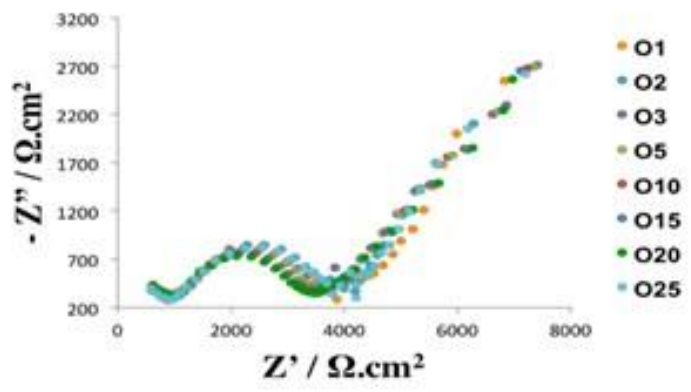

$600{ }^{\circ} \mathrm{C}$

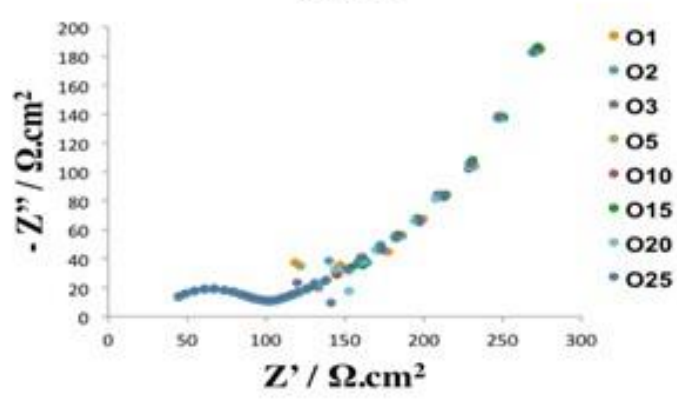

process in the overall SOFC-cathode mechanism is for the oxygen reduction reaction. This process is often referred to as the surface exchange of oxygen, perhaps because it is still not known which of the many elementary reactions are rate limiting the overall reaction and in which order they occur. The surface exchange reaction is generally believed to consist of the following sub reactions (not elementary): $\mathrm{O}_{2}$ adsorption, $\mathrm{O}_{2}$ dissociation, and integration of oxide ion species into the lattice and the reduction of either diatomic or mono-atomic oxygen species. The reduction reaction is generally considered to proceed simultaneously with the other reactions to form arbitrarily charged surface species depending on which reaction is the rate-limiting step and there is much recognition in literature. To understand the ORR mechanism, the complex impedance measurements were completed on a selected number of compositions, versus the value of oxygen partial pressure, $\mathrm{PO}_{2}$, at different temperatures.
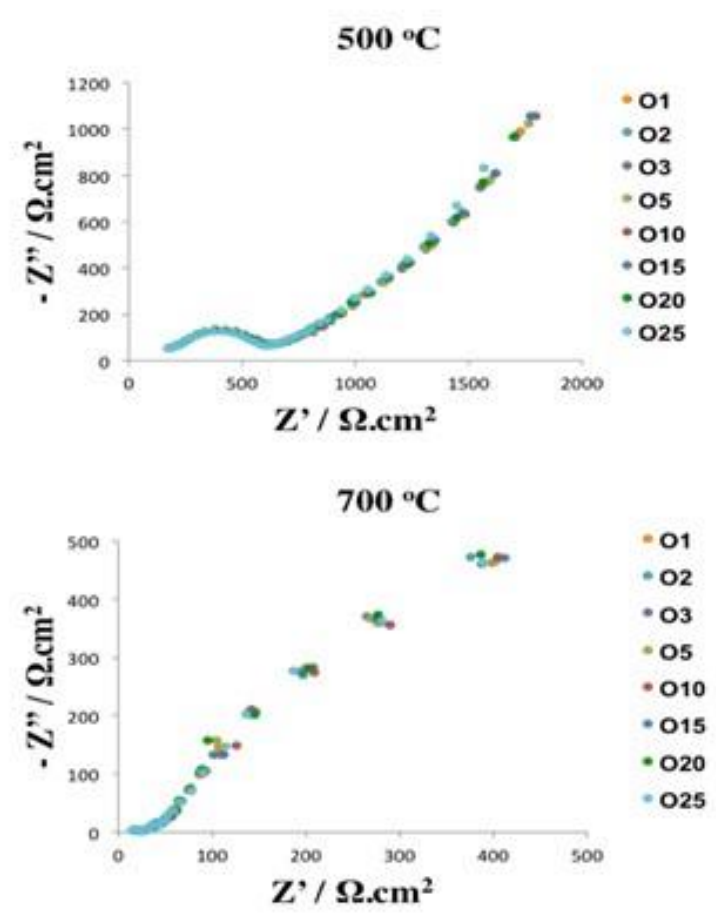

$800{ }^{\circ} \mathrm{C}$

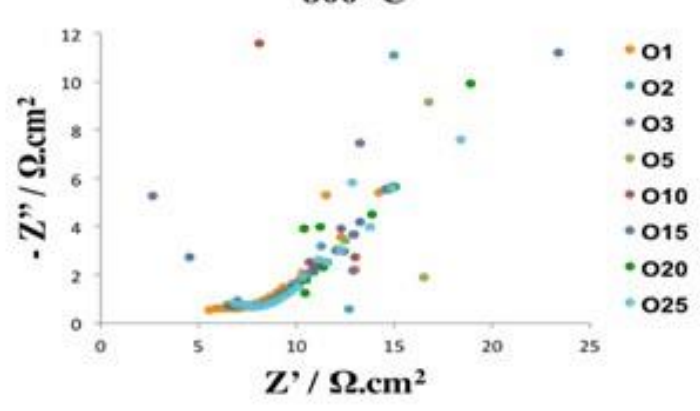

Figure 10. Complex impedance plots for LV05SC/YSZ/LV05SC symmetric cell at between $400-800{ }^{\circ} \mathrm{C}$ for different oxygen partial pressures. 
Figure 10 displays the selected impedance results for the solid crystal LV05SC electrode on the YSZ electrolyte that is measured under various oxygen partial pressure values and collected in each $50{ }^{\circ} \mathrm{C}$ increments in the range of temperature between 400 and $800{ }^{\circ} \mathrm{C}$.

EIS diagrams are comprised of arcs found in high frequency and low frequency regions, correspondingly. This indicates that as a minimum of two singular steps engaged in the ORR on the cathode. It is clearly seen that below the $500{ }^{\circ} \mathrm{C}$, two clear arcs are perceived in the high frequency part of the Nyquist graphs. While

$400{ }^{\circ} \mathrm{C}$

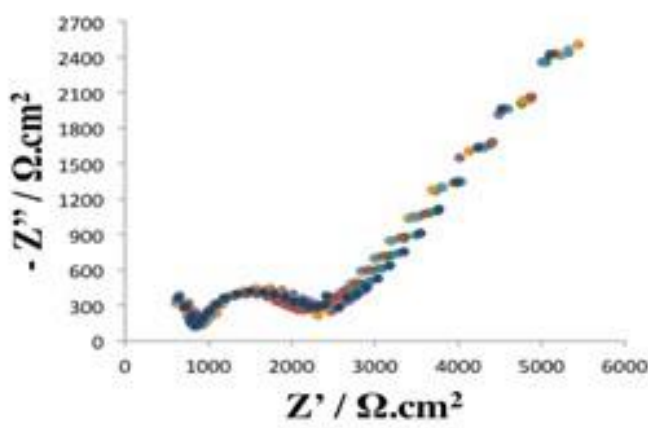

$600{ }^{\circ} \mathrm{C}$

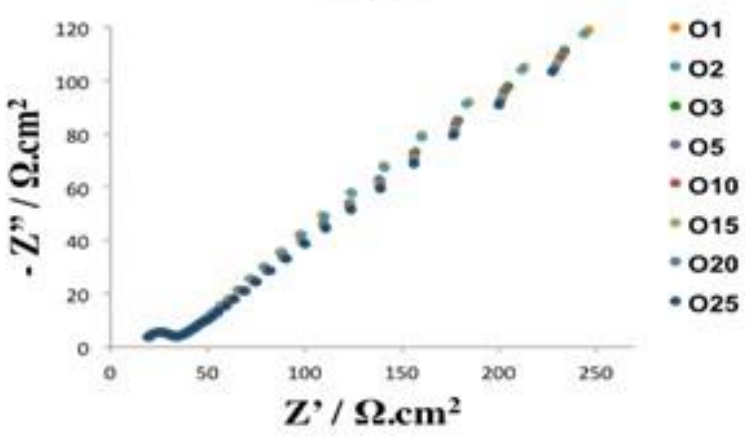

rising working temperature, the size of highfrequency semi-circle reduced remarkably, and the semi-circle was completely vanished at 500 ${ }^{\circ} \mathrm{C}$. Both the electrodes and electrolyte shape the impedance spectrum of a symmetric cell. The electrolyte typically exhibits behavior as an ideal resistor, which signifies the intercept resistance in the impedance graph at higher frequency region with the real impedance axis. With the decline in working temperature, an arc related to the oxide ion diffusion near the electrolyte grain boundary appeared in the higher frequency region.
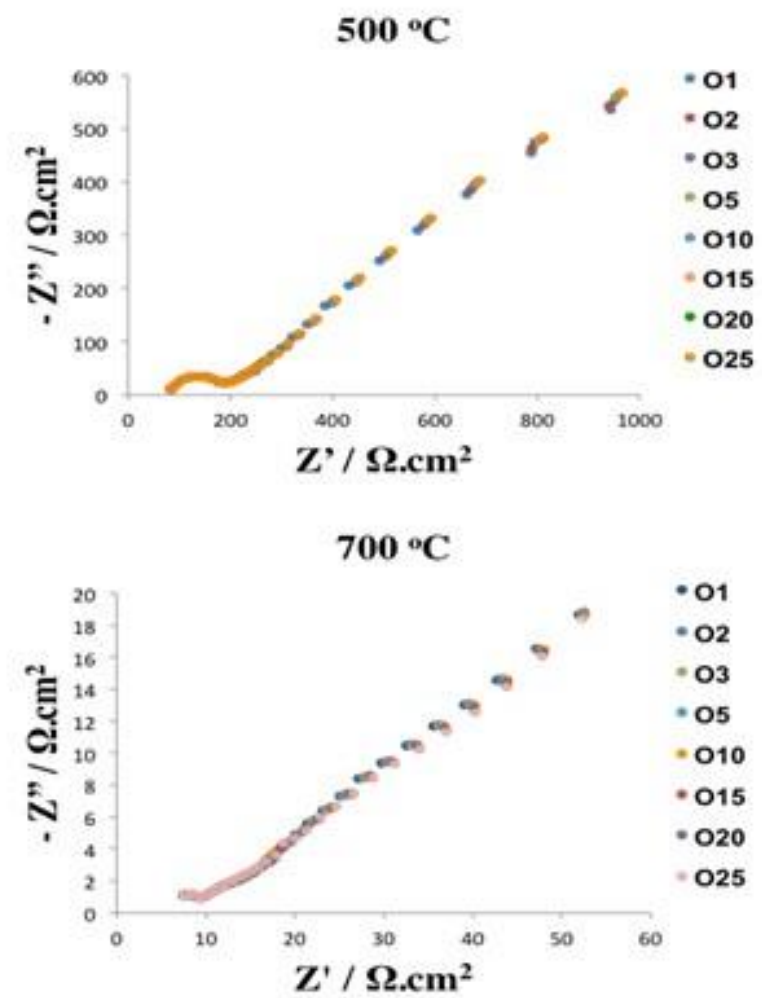

$800{ }^{\circ} \mathrm{C}$

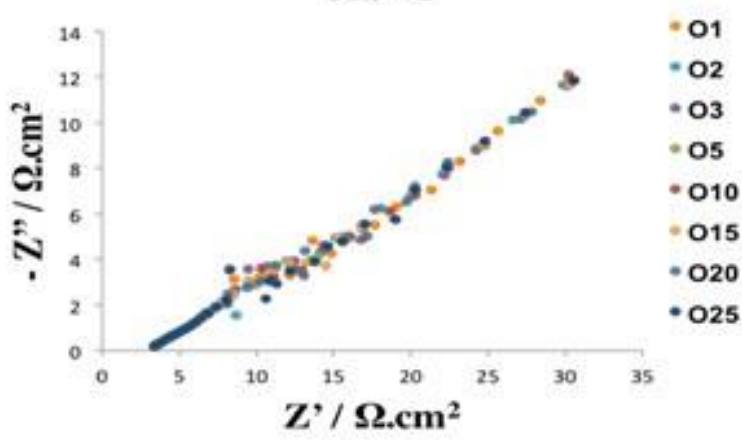

Figure 11. Complex impedance plots for LV05SM/YSZ/LV05SM symmetric cell at between $400-800{ }^{\circ} \mathrm{C}$ for different oxygen partial pressures.

Figure 11 shows the impedance responses for the solid crystalline LV05SM cathode on the YSZ electrolyte that is measured in various oxygen partial pressure values and collected in each 50 ${ }^{\circ} \mathrm{C}$ increments in the temperature region of $400-$ $800^{\circ} \mathrm{C}$.
It is clearly grasped in Figure 11 that the higher frequency region of the two obvious arcs of impedance parts has a clear form in the Nyquist plots below the $500{ }^{\circ} \mathrm{C}$. With rising working temperature, the higher frequency arc size is reduced noticeably, and this arc is entirely extinct at $500{ }^{\circ} \mathrm{C}$. An extra arc at the lower frequency region emerged when the working temperature 
was elevated to $700{ }^{\circ} \mathrm{C}$. The symmetric cell impedances can result from both the cathodes and electrolyte. The electrolyte classically executes as a perfect resistor and exhibits only a spot in the Nyquist graphs at higher temperature
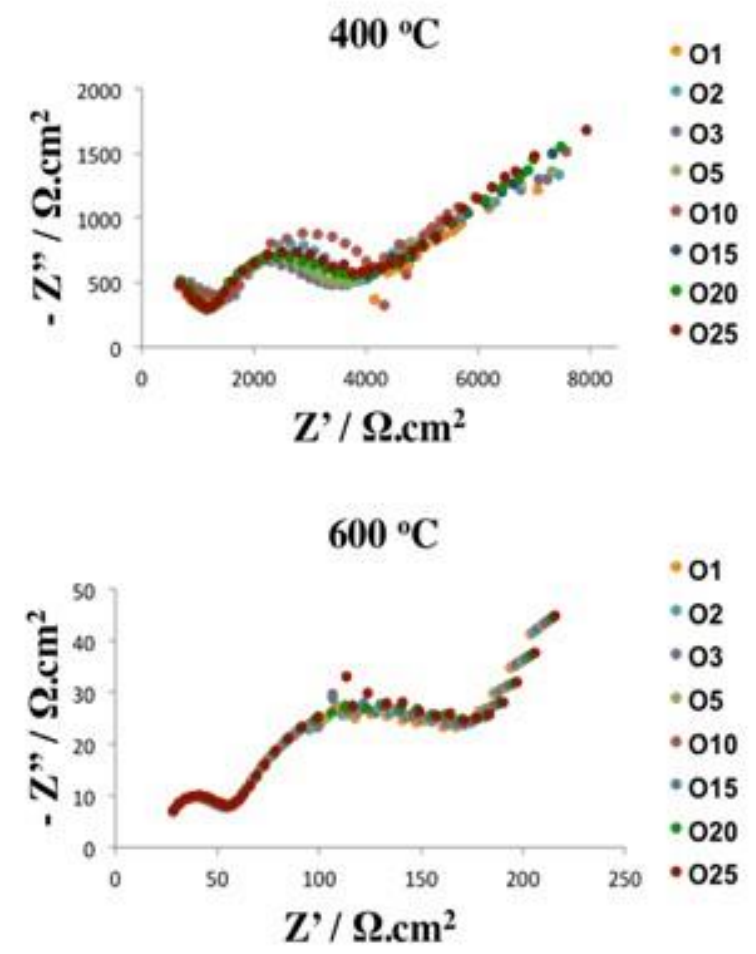

range in the inspected frequency region of $10^{6}$. $10^{-1} \mathrm{~Hz}$. Though, an arc correlated with the oxide ion diffusion near the electrolyte grain boundary also emerged in the higher frequency region with decline in working temperature.
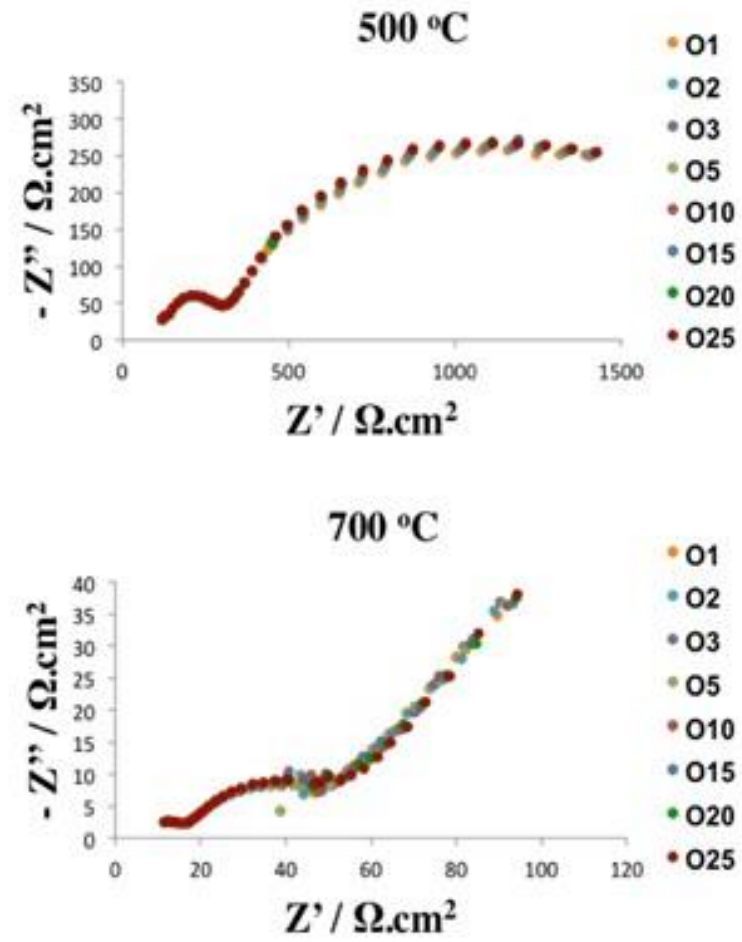

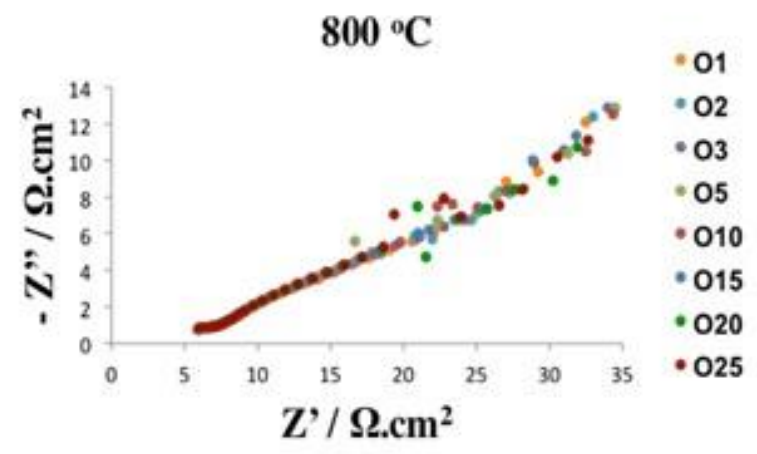

Figure 12. Complex impedance plots for LV3SF/YSZ/LV3SF symmetric cell at between $400-800{ }^{\circ} \mathrm{C}$ for different oxygen partial pressures.

Figure 12 shows some impedance responses for the solid crystalline LV3SF electrode on the YSZ electrolyte that is measured with various oxygen partial pressure values and collected in each 50 ${ }^{\circ} \mathrm{C}$ increments in temperature between 400 to $800^{\circ} \mathrm{C}$. From the Figure 12 , it is clearly seen that below the $500{ }^{\circ} \mathrm{C}$, two impedance contributions have an apparent shape in the high frequency part of the Nyquist graphs. With rising working temperature, the size of higher frequency arc is reduced importantly, and the arc was fully vanished at $500{ }^{\circ} \mathrm{C}$. An extra arc at the range of lower frequency emerged when the working temperature was raised to $600^{\circ} \mathrm{C}$. The symmetric cell impedances can be resulted from both the cathodes and electrolyte. The electrolyte typically performs as a perfect resistor, which denotes the intercept point in the impedance graph at higher frequency region with the real axis. Yet, with the reduction in working temperature, an arc related to oxide ion transfer on the surface near the electrolyte grain boundary also performed in the high frequency region.

The merely ohmic part of the electrode resistance is called polarization resistance $(R p)$. This may be calculated as the sum of the resistances of all separate processes $\left(R p=R_{1}+R_{2}+R_{3} \ldots+R n\right)$. The experimental polarization resistance for the symmetrical cell reveals the addition of the polarization resistance of the two different cathodes explored. Consequently, all the cell impedances were standardized by the electrode area $\left(0.04 \mathrm{~cm}^{2}\right)$, so the $R$ parameter attained in 
fitting for each parameter were divided by two to deliberate the influence of the two electrodes, therefore, $\mathrm{R}$ parameter called area specific resistance (ASR).

This is well identified that various courses for ORR on mixed ionic and electronic conducting electrodes with different relationships are affected by oxygen partial pressure. The most frequently employed factor to define the ratelimiting step in ORR is $n$, which specifies the relationship between the cathode resistance and oxygen partial pressure displayed in Figure 13. The $n$ value presents evidence concerning the species elaborated in the electrode reaction. The overall ORR may be summarized as $\mathrm{O}_{2}$ converted into $2 \mathrm{O}^{2-}$ ions by accepting four electrons. This is an intricate multi-phase reaction, in which practically contains the gas diffusion, surface adsorption/dissociation and charge transfer steps. Generally, on behalf of metal oxides having solid electrolytes, $n=1$ can be credited to gas diffusions and adsorptions of oxygen as a restrictive step; $n=1 / 2$ linked to the oxygen adsorption-desorption step, linking oxygen diffusion at the border of gas/cathode and surface diffusion of connected to intermediate oxide species as a limiting stage; and $n=3 / 8$ deduced a process coordinated by the atomic oxygen diffusion step (beside the two stages electrode/electrolyte contact) continued by a charge transfer as a limiting step; $n=1 / 4$ associated to the charge transfer step on the electrode, happening at the boundaries of current collector/electrode and the electrode/electrolyte as a limiting step; and $n=1 / 8$ stated to the production of oxide ions as the intermediate species as a restrictive process; and $n=1 / 10$ or $n=0$ can be recognized to the oxide ion diffusion from the triple phase boundary (TPB) to solid electrolyte, correspondingly.

The ASR estimates for oxygen reduction reaction are calculated via the addition of separate resistances related with every single step. Like anticipated, the ASR for LV05SC/YSZ boundary declines particularly with rising temperature and marginally with the oxygen partial pressure as revealed in Figure 13. The feature of ASR displays rather weak $\mathrm{PO}_{2}$ reliance $(n=0.3022-0.5212)$, which would be associated to oxygen adsorptiondesorption steps or a step coordinated by the atomic oxygen diffusion (beside the two phases electrode/electrolyte contact) trailed by a charge transfer. Consequently, these two steps are the main rate-limiting processes for LV05SC cathode. As projected, the ASR for LV05SM/YSZ interface drops remarkably with rising temperature and marginally with the oxygen partial pressure as illustrated in Figure 13. The property of ASR confirms very weak $\mathrm{PO}_{2}$ dependence $(n=0.0042$ - 0.0607), which would be correlated to the oxide ion transfer within the electrode bulk and/or from electrode to YSZ electrolyte through the TPB. Therefore, this process can be considered as the main rate-limiting step for LV05SM. Like accepted, the ASR for LV3SF/YSZ boundary reduces outstandingly with rising temperature and faintly with the oxygen partial pressure as seen in Figure 13. The representation of ASR indicates also very weak $\mathrm{PO}_{2}$ dependence $(n=$ $0.0053-0.0426$ ), which would be linked to the oxide ion transfer within the bulk electrode and/or from electrode to electrolyte through the TPB. Consequently, this step can be deliberated as the main rate- limiting step for LV3SF material.

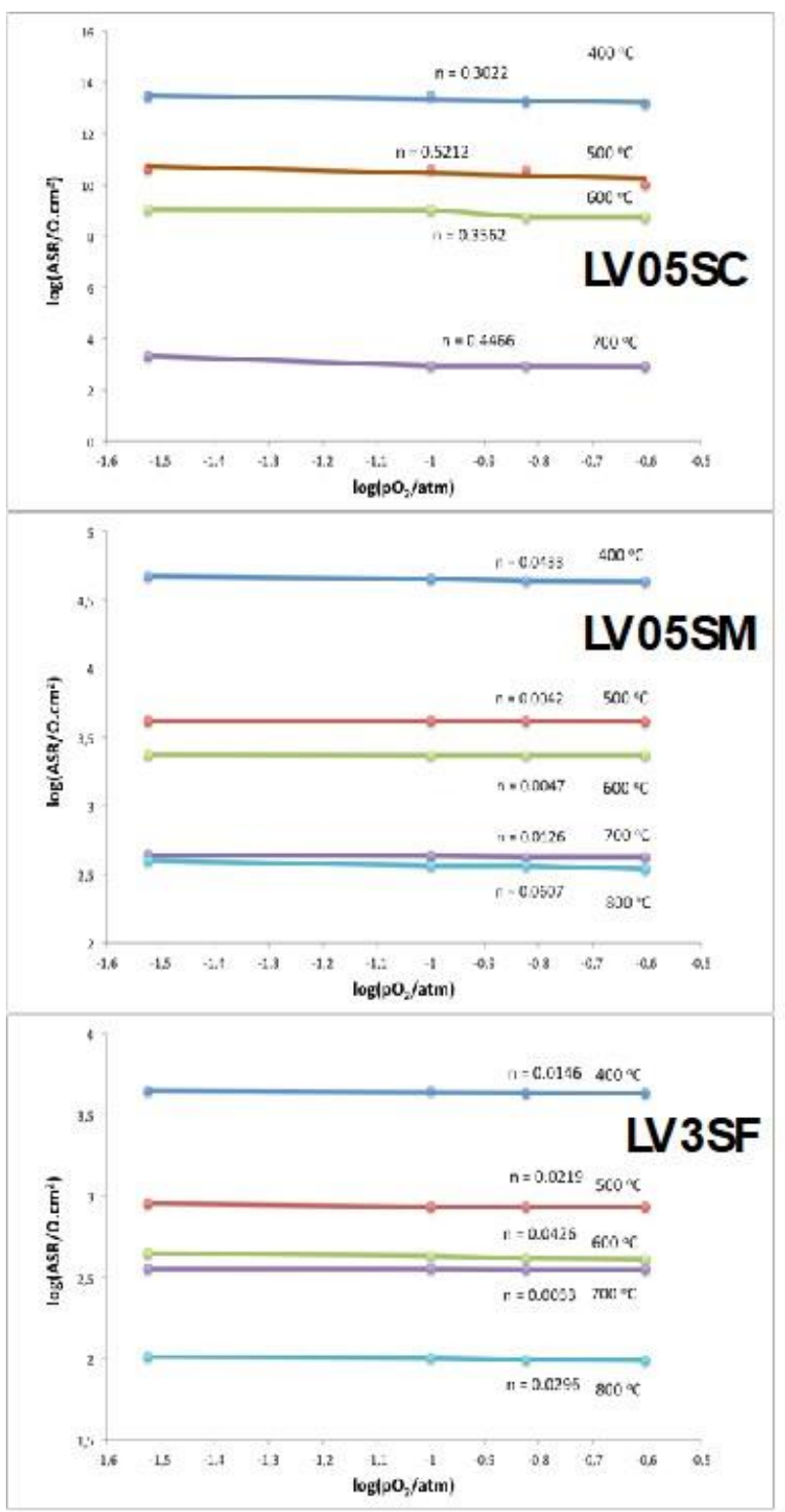

Figure 13. The dependence of the area specific resistance of the LV05SC/YSZ, LV05SM/YSZ, and LV3SF/YSZ interfaces as a function of oxygen partial pressure at different temperatures.

\section{CONCLUSION}

This study deals with fundamental experimental analysis on mixed electronic and ionic conducting model perovskite cathode electrodes, in particular for the application as catalytically active cathode in SOFC systems. As an SOFC cathode candidate, the stability of the developed cathode materials 
with regard to the application was first studied on materials synthesized from the metal nitrates by the sol-gel process. XRD results reveals a crystalline perovskite structure for all materials with a rhombohedral unit cell. All peaks in the XRD pattern of the cathode samples are relatively visible, demonstrating well-incorporated into crystal lattice of the metal oxides employed in the preparation. XPS analyses show that the oxidation states of metals in the composition of the surface of the samples were confirmed. According to advance conductivity studies, the materials exhibit high conductivities and all compositions except LV05SC showed metal-like temperature dependences i.e. decrease in conductivity with temperature. While in the studied temperature region, the electrical conductivity is augmented with rising temperature for LV05SM, typical of semiconductor behavior. In the case of LV3SF sample, with rising temperature the conductivity grows and extents to maximum value at about $500{ }^{\circ} \mathrm{C}$. The low value of activation energy emphasizes the high catalytic activity of the electrode material. Vanadium doped LSM sample (LV05SM) has the lowest conductivity value of $14.8 \mathrm{~S} / \mathrm{cm}$ with activation energy of $0.20 \mathrm{eV}$ and it continues with LV3SF material with a value of $26.23 \mathrm{~S} / \mathrm{cm}$ and Ea of $0.14 \mathrm{eV}$.

The electrolyte classically acts as a perfect electrical resistor and the oxide ion diffusion through the electrolyte material could be observed as an arc in the higher frequency range inside the impedance spectrum and it is independent of $\mathrm{PO}_{2}$. However, at lower temperatures the electrolyte becomes the limiting factor for SOFC applications. With diminishing in the partial pressure of oxygen, the impedance values rise considerably, particularly at lower frequency regions. For most of the impedance arcs, two steps could be deduced at higher and lower frequencies. It signifies that at least two electrochemical steps control the whole electrochemical reaction. The analysis of the effect of both the partial pressure of oxygen and the temperature in the electrode impedance was achieved and the data were fitted to the equivalent circuits in order to have more information to interpret properly steps included in the cathode/electrolyte interface. From the fitting parameters, it can be said that the resistances related to the kinetics of electrode steps decline with rising temperature.

The area specific resistance (ASR) analysis shows that oxide ion relocation within the cathode bulk is the main rate-limiting step for the LV05SM, and LV3SF cathode materials. The polarization resistance value for LV05SC material was associated to the oxygen adsorption-desorption steps or a step ordered by the atomic oxygen diffusion. Therefore, these two steps are the main rate-limiting processes for LV05SC cathode. The comparison of the polarization and impedance behavior of pronounced cathode materials under identical experimental conditions showed that the much higher electrode performance of LV3SF, and LV05SM compared to that of LV05SC is clearly due to their better ionic conductivity values. As a result of this study, it is concluded that these cathode materials would be candidates as IT-SOFC cathode materials.

\section{ACKNOWLEDGMENT}

The authors appreciatively acknowledge the financial supports provided by TUBITAK (Project Number: 112M279 and 214Z094) and Bogazici University, Scientific Research Projects (BAP) (Project Number: 5341-10B05S11).

\section{REFERENCES}

1. Lashtabeg A, Skinner SJ. Solid oxide fuel cells - a challenge for materials chemists? Journal of Materials Chemistry. 2006;16(31):3161-70.

2. Winter $M$, Brodd RJ. What are batteries, fuel cells, and supercapacitors? Chemical Reviews. 2004;104(10):4245-69.

3. Ormerod RM. Solid oxide fuel cells. Chemical Society Reviews. 2003;32(1):17-28.

4. Choudhury A, Chandra H, Arora A. Application of solid oxide fuel cell technology for power generation-A review. Renewable \& Sustainable Energy Reviews. 2013;20:430-42.

5. Baur E, Preis H. Über Brennstoff-Ketten mit Festleitern. Zeitschrift fur electrochemie. 1937;43(9):727.

6. Yamamoto O, Takeda Y, Kanno R, Noda M. Perovskite-Type Oxides As Oxygen Electrodes For High-Temperature Oxide Fuel-Cells. Solid State Ionics. $1987 ; 22(2-3): 241-6$.

7. Yamamoto O. Solid oxide fuel cells: fundamental aspects and prospects. Electrochimica Acta. 2000;45(15-16):2423-35.

8. Wachsman ED, Lee KT. Lowering the Temperature of Solid Oxide Fuel Cells. Science. 2011;334(6058):935-9.

9. Brett DJL, Atkinson A, Brandon NP, Skinner SJ. Intermediate temperature solid oxide fuel cells. Chemical Society Reviews. 2008;37(8):1568-78.

10. Istomin SY, Antipov EV. Cathode materials based on perovskite-like transition metal oxides for intermediate temperature solid oxide fuel cells. Russian Chemical Reviews. 2013;82(7):686-700.

11. Tsipis EV, Kharton VV. Electrode materials and reaction mechanisms in solid oxide fuel cells: a brief review. Journal of Solid State Electrochemistry. 2008;12(9):1039-60. 
12. Sun CW, Hui R, Roller J. Cathode materials for solid oxide fuel cells: a review. Journal of Solid State Electrochemistry. 2010;14(7):1125-44.

13. Tezuka $K$, Hinatsu $Y$, Nakamura $A$, Inami $\mathrm{T}$, Shimojo $\mathrm{Y}$, Morii $\mathrm{Y}$. Magnetic and neutron diffraction study on perovskites La1-xSrxCrO3. Journal of Solid State Chemistry. 1998;141(2):404-10.

14. Sengodan S, Choi S, Jun A, Shin TH, Ju YW, Jeong HY, et al. Layered oxygen-deficient double perovskite as an effcient and stable anode for direct hydrocarbon solid oxide fuel cells. Nature Materials. 2015;14(2):205-9.

15. Carpanese MP, Clematis D, Bertei A, Giuliano A, Sanson A, Mercadelli E, et al. Understanding the electrochemical behaviour of LSM-based SOFC cathodes. Part I - Experimental and electrochemical. Solid State Ionics. 2017;301:106-15.
16. Mizusaki J, Mori N, Takai $\mathrm{H}$, Yonemura $\mathrm{Y}$, Minamiue $H$, Tagawa $H$, et al. Oxygen nonstoichiometry and defect equilibrium in the perovskite-type oxides La1-xSrxMnO3+d. Solid State Ionics. $2000 ; 129(1-4): 163-77$.

17. De Souza RA, Kilner JA, Walker JF. A SIMS study of oxygen tracer diffusion and surface exchange in La0.8Sr0.2MnO3+delta. Materials Letters. $2000 ; 43(1-2): 43-52$.

18. Chen YB, Shen J, Yang GM, Zhou W, Shao ZP. A single-/double-perovskite composite with an overwhelming single-perovskite phase for the oxygen reduction reaction at intermediate temperatures. Journal of Materials Chemistry $A$. 2017;5(47):24842-9. 
